\title{
Staphylococcus aureus subsp. anaerobius strain ST1464 genome sequence
}

\author{
Haitham Elbir ${ }^{1}$, Catherine Robert ${ }^{1}$, Ti Thien Nguyen ${ }^{1}$, Grégory Gimenez ${ }^{1}$, Sulieman M. El \\ Sanousi ${ }^{2}$, Jan-Ingmar Flock ${ }^{3}$, Didier Raoult ${ }^{1}$, Michel Drancourt ${ }^{1}$ \\ ${ }^{1}$ Aix Marseille Université, URMITE, Marseille, France \\ ${ }^{2}$ Faculty of Veterinary Medicine, University of Khartoum, Sudan \\ ${ }^{3}$ Department of Microbiology, Tumor and Cell Biology, Stockholm, Sweden \\ Corresponding author: Professor Michel Drancourt, (Michel.Drancourt@univmed.fr)
}

Keywords: Staphylococcus aureus subsp. anaerobius, genome, SOLiD, Morel's disease.

\begin{abstract}
Staphylococcus aureus subsp. anaerobius is responsible for Morel's disease in animals and a cause of abscess in humans. It is characterized by a microaerophilic growth, contrary to the other strains of $S$. aureus. The 2,604,446-bp genome (32.7\% GC content) of S. anaerobius ST1464 comprises one chromosome and no plasmids. The chromosome contains 2,660 open reading frames (ORFs), 49 tRNAs and three complete rRNAs, forming one complete operon. The size of ORFs ranges between 100 to 4,600 bp except for two ORFs of 6,417 and 7,173 bp encoding segregation ATPase and non-ribosomal peptide synthase, respectively. The chromosome harbors Staphylococcus phage 2638A genome and incomplete Staphylococcus phage genome PT1028, but no detectable CRISPRS. The antibiotic resistance gene for tetracycline was found although Staphylococcus aureus subsp. anaerobius is susceptible to tetracycline in-vitro. Intact oxygen detoxification genes encode superoxide dismutase and cytochrome quinol oxidase whereas the catalase gene is impaired by a stop codon. Based on the genome, in-silico multilocus sequence typing indicates that $S$. aureus subsp. anaerobius emerged as a clone separated from all other $S$. aureus strains, illustrating host-adaptation linked to missing functions. Availability of $S$. aureus subsp. anaerobius genome could prompt the development of post-genomic tools for its rapid discrimination from $S$. aureus.
\end{abstract}

\section{Introduction}

Staphylococcus aureus subsp. anaerobius (here referred as $S$. aureus subsp. anaerobius) is a Gram positive bacterium of veterinary interest and is responsible for Morel's disease, which is characterized by chronic subcutaneous abscesses near superficial lymph nodes in sheep and goat [1]. Morel's disease was described in Sudan, Saudi Arabia, Hungary, Spain, Denmark, Italy and Poland [1-7]. The only report of human infection was a case of septicemia in an Australian patient [8]. The causative agent of the disease is clonal and most of Morel's disease cases in the world are due to oxacillin-susceptible $S$. aureus subsp. anaerobius sequence type ST1464 [6]. The disease remains neglected and is rarely investigated in laboratory. Accordingly, the availability of the $S$. aureus subsp. anaerobius genome sequence may facilitate the development of molecular tools to improve the diagnosis and characterization of Morel's disease. Here we present a description of the complete genome sequence of $S$. aureus subsp. anaerobius strain ST1464 and its annotation, as well as a preliminary comparative analysis with the $S$. aureus subsp. aureus genome.

\section{Classification and features}

The $S$. aureus subsp. anaerobius strain ST1464 sequenced in this study was isolated from an abscess in the prescapular region of a sheep with Morel's disease in Khartoum state, Sudan [6]. $S$. aureus subsp. anaerobius is a Gram-positive, coccus-shaped bacterium (Figure 1 and Table 1) growing at $37{ }^{\circ} \mathrm{C}$ in a microaerophilic atmosphere containing $<8 \%$ oxygen. 


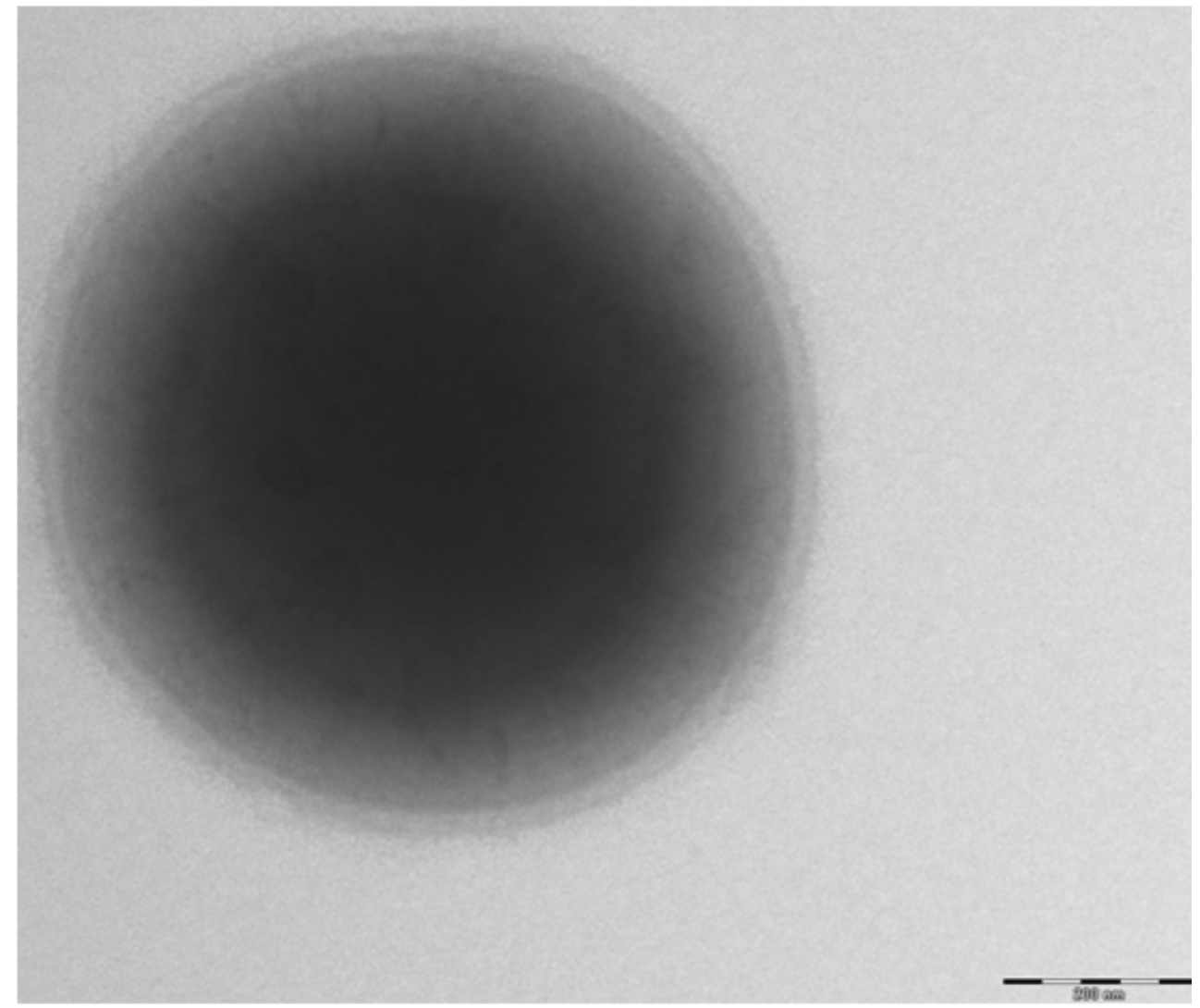

Figure 1. Transmission electron microscopy of $S$. aureus subsp. anaerobius strain st1464, using a Morgani 268D (Philips) at an operating voltage of $60 \mathrm{kV}$. The scale bar represents $900 \mathrm{~nm}$.

Biochemical features include positive tests for tube coagulase and DNase, negative tests for catalase, citrate, urease and ornithine decarboxylase. Using commercial Pheneplate system (PhPlate Microplate Techniques AB, Stockholm, Sweden) [25], positive reactions were obtained for fructose, sucrose and weak reaction for mannose, inosine and ribose. Negative reaction were observed for mannonic acid lacton L-arabinose, D- xylose, galactose, maltose, cellobiose, trehalose, palatinose, lactose, melibiose, lactulose, gentobiose, melezitose, raffinose, adonitol, Darabitol, glycerol, maltitol, sorbitol, dulcitol, sorbose, deoxy-glucose, deoxy-ribose, rhamnose, D-fucose, L-fucose, tagatose, amygdalin, arbutin, keto-gluconate, gluconate, melbionate, galacturonic lacton, salicine, fumarate, malinate, malonate, pyruvate, tartarate, mannitol and xylitol. The type strain is deposited in the German Collection of Microorganisms and Cell Culture (DSMZ) as DSM 20714. The ST1464 strain exhibited a $99 \%$ nucleotide sequence similarity with the
Staphylococcus aureus 16S rRNA gene (Genbank accession number D83357.1) (Figure 2).

Matrix-assisted laser desorption/ionization timeof-flight mass spectrometry (MALDI-TOF-MS) (Brüker Daltonics, Bremen, Germany) was used as previously described [27]. Briefly, a pipette tip was used to pick one $S$. aureus subsp. anaerobius colony from a $5 \%$ blood agar plate and to spread it on a MTP 384 MALDI-TOF target plate (Brüker Daltonics). Smears were overlaid with $1.5 \mu \mathrm{L}$ of matrix solution (saturated solution of alphacyano-4-hydroxycinnamic acid) in 50\% acetonitrile, $2.5 \%$ tri-fluoracetic-acid and allowed to dry. MALDI-TOF without bacteria was used as a negative control and the positive control consisted of $1.5 \mu \mathrm{L}$ of Brüker Bacterial Test Standard, a protein extract of Escherichia coli DH5alpha. Negative control spots remained negative and the positive control spots were identified as E. coli with score $>2$, however, the $\mathrm{S}$. aureus subsp. anaerobius spots yielded a score of 2.1 with the reference spectra of S. aureus subsp. anaerobius (Figure 3). 
Table 1. Classification and general features of $S$. aureus subsp anaerobius strain ST1464 according to the MIGS recommendations [9].

\begin{tabular}{|c|c|c|c|}
\hline MIGS ID & Property & Term & Evidence code $^{\mathrm{a}}$ \\
\hline & \multirow{8}{*}{ Current classification } & Domain Bacteria & TAS [10] \\
\hline & & Phylum Firmicutes & TAS [11-13] \\
\hline & & Class Bacilli & TAS $[14,15]$ \\
\hline & & Order Bacillales & TAS $[16,17]$ \\
\hline & & Family Staphylococcaceae & TAS $[18,19]$ \\
\hline & & Genus Staphylococcus & TAS $[16,20-22]$ \\
\hline & & Species Staphylococcus aureus subsp. anaerobius & TAS [1] \\
\hline & & Strain ST1464 & TAS [7] \\
\hline & Gram stain & Positive & TAS [23] \\
\hline & Cell shape & Coccus & TAS [23] \\
\hline & Motility & Nonmotile & TAS [23] \\
\hline & Sporulation & Nonsporulating & TAS [23] \\
\hline & Temperature range & $30-40^{\circ} \mathrm{C}$ & TAS [23] \\
\hline & Optimum temperature & $37^{\circ} \mathrm{C}$ & TAS [1] \\
\hline MIGS-6.3 & Salinity & Tolerates $10 \% \mathrm{NaCl}$ & TAS [1] \\
\hline \multirow[t]{3}{*}{ MIGS-22 } & Oxygen requirement & Microaerophilic & TAS [1] \\
\hline & Carbon source & Fructose, sucrose & NAS \\
\hline & Energy source & Fructose, sucrose & NAS \\
\hline MIGS-6 & Habitat & Subcutaneous abscess & TAS [1] \\
\hline MIGS-15 & Biotic relationship & free living & NAS \\
\hline \multirow[t]{3}{*}{ MIGS-14 } & Pathogenicity & Yes & NAS \\
\hline & Biosafety level & 2 & NAS \\
\hline & Isolation & Sheep abscess & TAS [1] \\
\hline MIGS-4 & Geographic location & Sudan & TAS [1] \\
\hline MIGS-5 & Sample collection time & September 2005 & IDA \\
\hline MIGS-4.1 & Latitude & $15.656^{\prime} \mathrm{N}$ & IDA \\
\hline MIGS-4.1 & Longitude & $32.548^{\prime} \mathrm{E}$ & IDA \\
\hline MIGS-4.3 & Depth & Surface & IDA \\
\hline MIGS-4.4 & Altitude & $382 \mathrm{~m}$ above sea level & IDA \\
\hline
\end{tabular}

aEvidence codes - IDA: Inferred from Direct Assay; TAS: Traceable Author Statement (i.e., a direct report exists in the literature); NAS: Non-traceable Author Statement (i.e., not directly observed for the living, isolated sample, but based on a generally accepted property for the species, or anecdotal evidence). These evidence codes are from the Gene Ontology project [24]. 


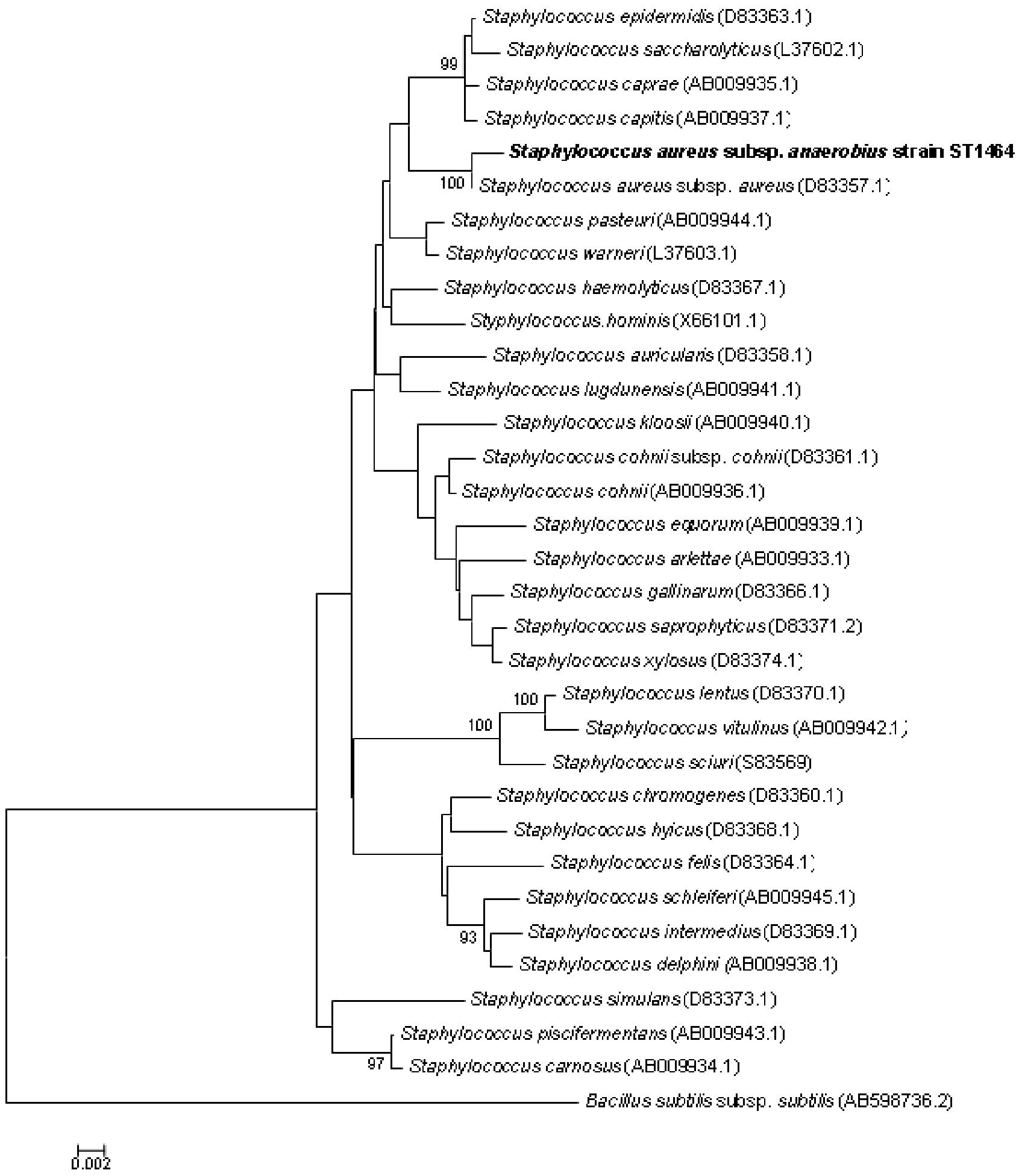

Figure 2. Phylogenetic tree depicting the relationship between Staphylococcus aureus subsp. anaerobius and other members of the genus Staphylococcus based on 1,311 base pairs of the 16S rRNA gene sequence aligned in Muscle. The tree was constructed by using the Neighbor-Joining method and Kimura 2-parameter model using MEGA5 software [26] and rooted with Bacillus subtilis subsp. subtilis. Bootstrap consensus trees were inferred from 100 replicates, only bootstrap values $>90 \%$ were indicated. 


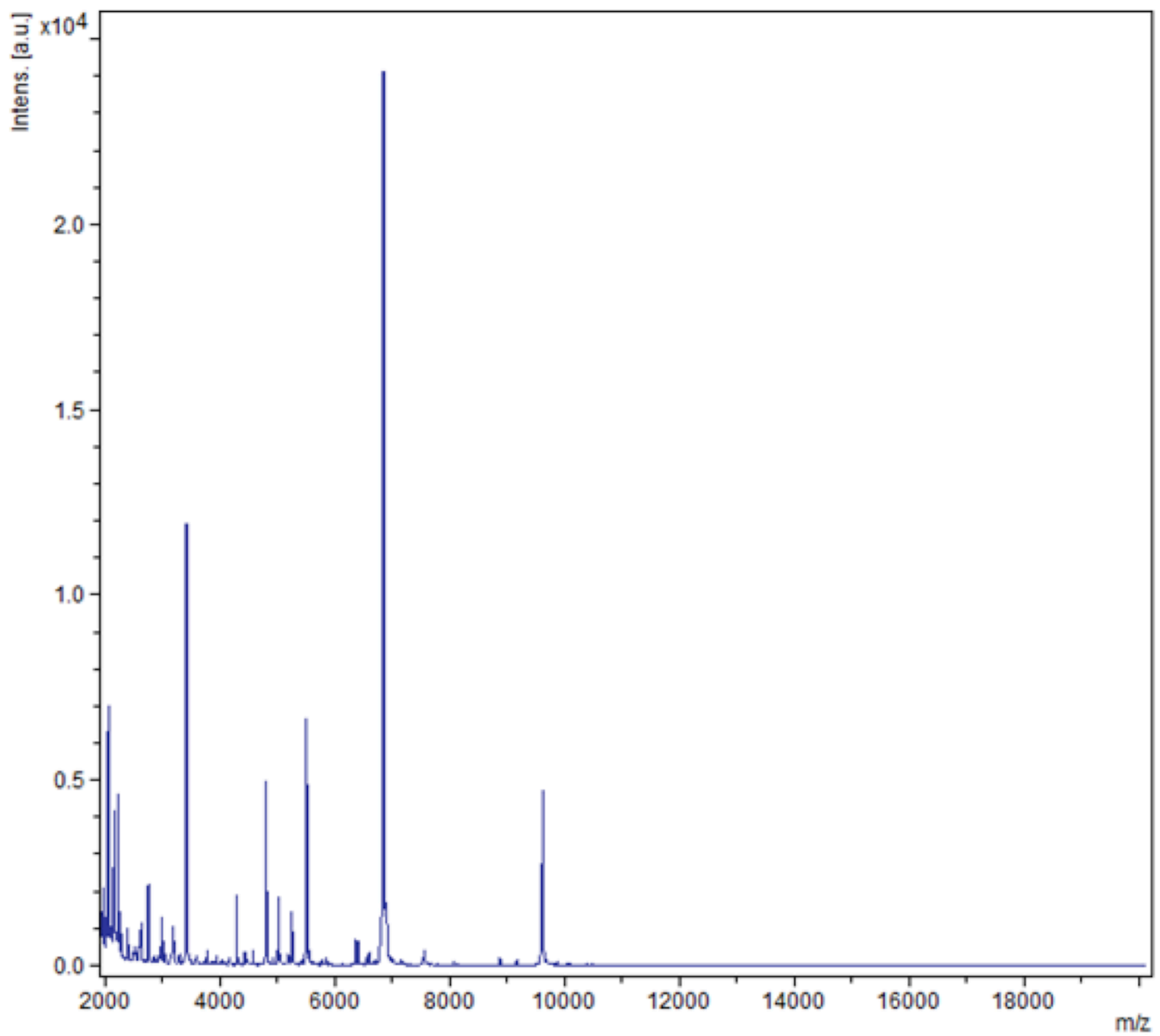

Figure 3. Reference mass spectrum from S. aureus subsp. anaerobius strain ST1464. Spectra from 4 individual colonies were compared and a reference spectrum was generated.

\section{Genome sequencing and annotation}

\section{Genome project history}

The organism was selected for sequencing on the basis of its economic importance in animal trade and public health. This Whole Genome Shotgun project has been deposited at DDBJ/EMBL /GenBank under the accession ANIT00000000. The version described in this paper is the first version, ANIT01000000. It consists of 100 large contigs. Table 2 shows the project information.

\section{Growth conditions and DNA isolation}

$S$. aureus subsp. anaerobius was grown in microaerophilic atmosphere on 5\% sheep bloodenriched Columbia agar (bioMérieux, Marcy
l'Etoile, France) at $37^{\circ} \mathrm{C}$. Two hundred microliters of bacterial suspension were diluted into $1 \mathrm{~mL}$ Tris EDTA buffer and incubated with lysozyme for 30 minutes at $37^{\circ} \mathrm{C}$ followed by an overnight incubation with Proteinase $\mathrm{K}$ at $37^{\circ} \mathrm{C}$. DNA was purified by three successive phenol-chloroform extractions and ethanol precipitation at $-20^{\circ} \mathrm{C}$ overnight. After centrifugation, the DNA was resuspended in $52 \mu \mathrm{L}$ TE buffer. DNA concentration was measured by the Quant-it Picogreen kit (Invitrogen Saint Aubin, France) on the Genios_Tecan fluorometer at 60 $\mathrm{ng} / \mu \mathrm{L}$. 


\begin{tabular}{lll}
\multicolumn{2}{l}{ Table 2. Genome sequencing project } & information \\
\hline MIGS ID & Property & Term \\
\hline MIGS-31 & Finishing quality & High-quality draft \\
MIGS-28 & Libraries used & One 454 paired end 3-kb library \\
MIGS-29 & Sequencing platforms & 454 GS FLX Titanium \\
MIGS-31.2 & Sequencing & $24 \times$ \\
MIGS-30 & Assemblers & Newbler version 2.5.3 \\
MIGS-32 & Gene calling method & Prodigal \\
& INSDC ID & PRJNA178987 \\
& Genbank ID & ANIT00000000 \\
& Genbank Date of Release & March 3, 2013 \\
& Gold ID & Gi21982 \\
MIGS-13 & Project relevance & Vaccine development
\end{tabular}

\section{Genome sequencing and assembly}

Mechanical fragmentation of three $\mu \mathrm{g}$ of DNA was done on the Covaris device (KBioScience-LGC Genomics, Teddington, UK) using miniTUBE-Red $5 \mathrm{~Kb}$. DNA fragmentation was visualized using an Agilent 2100 BioAnalyzer on a DNA labchip 7500 with an optimal size of $3.2 \mathrm{~kb}$. The library was constructed according to the 454 Titanium paired end protocol (Roche Applied Science, Mannheim, Germany). Circularization and nebulization generated a pattern with an optimum at $5,72 \mathrm{bp}$. After PCR amplification through 17 cycles followed by double size selection, the single stranded paired end library was quantified on the Quant-it Ribogreen kit (Invitrogen, Saint Aubin, France) on a Genios Tecan fluorometer at $1620 \mathrm{pg} / \mu \mathrm{L}$. The library concentration equivalence was calculated as $2.61 \mathrm{E}+09$ molecules $/ \mu \mathrm{L}$. The library was stocked at $-20^{\circ} \mathrm{C}$ until used. The library was clonally amplified with $0.5 \mathrm{cpb}$ and $1 \mathrm{cpb}$ in two emPCR reactions respectively with the GS Titanium SV emPCR Kit (Lib-L) v2 (Roche). Yields of the emPCR were $10.76 \%$ and $14.04 \%$ for each semPCR condition. A total of 790,000 beads were loaded on the GS Titanium PicoTiterPlate PTP Kit $70 \times 75$ and sequenced with the GS Titanium Sequencing Kit XLR70 (Roche Applied Science, Mannheim, Germany). The run was performed overnight and then analyzed on the cluster through the gsRunBrowser and gsAssembler (Roche). A total of 230,000 passed filter wells were obtained and generated $80.57 \mathrm{Mb}$ with an average 350-bp length. The passed-filter sequences were assembled on the gsAssembler from Roche with $90 \%$ identity and 40 -bp overlap. Assembly yielded six scaffolds and 100 large contigs
(> 500-bp), generating $24 \times$ genome equivalents of a $2.6 \mathrm{Mb}$-genome.

\section{Genome annotation}

The prodigal program was used to predict open reading frames (ORFs) from the 100 large contigs [28]. tRNAs were predicted using the Aragorn program [29] and rRNAs were predicted using RNAmmer. The predicted genes were Blasted against the non-redundant database. The functional annotation of predicted ORFs was performed using RPS-BLAST [30] against the cluster of orthologous groups (COG) database [31] and Pfam database [32]. TMHMM program was used for gene prediction with transmembrane helices [33] and signalP program was used for prediction of genes with peptide signals [34]. PHAST software was used for bacteriophage detection [35]. To estimate the similarity at the genome level between S. aureus subsp. anaerobius strain ST1464 and $S$. aureus, BLASTP was performed for genes with query coverage $\geq 70 \%$ and identity $\geq 30 \%$.

\section{Genome properties}

The genome consists of one circular 2,604,446-bp chromosome without a plasmid with a $32.7 \% \mathrm{G}+\mathrm{C}$ content. It comprises 2,660 ORFs, 49 tRNAs and three complete rRNAs. A total of 2,120 genes (78.17\%) were assigned a putative function. The distribution of genes into COGs functional categories is presented in Table 3 and Figure 4. The properties and the statistics of the genome are summarized in Table 4. ORF sizes ranged between 100 to 4,600 bp except for a 6,417-bp chromosome segregation ATPase gene and a 7,173-bp non-ribosomal peptide synthetase gene (Figure 5). 
Table 3. Number of genes associated with the 25 general COG functional categories

\begin{tabular}{|c|c|c|c|}
\hline Code & Value & $\%$ age $^{a}$ & Description \\
\hline$J$ & 147 & 5.53 & Translation, ribosomal structure and biogenesis \\
\hline A & 0 & 0 & RNA processing and modification \\
\hline K & 185 & 6.95 & Transcription \\
\hline L & 115 & 4.32 & Replication, recombination repair \\
\hline B & 2 & 0.08 & Chromatin structure dynamics \\
\hline $\mathrm{D}$ & 23 & 0.86 & Cell cycle control, mitosis meiosis \\
\hline Y & 0 & 0 & Nuclear structure \\
\hline $\mathrm{V}$ & 59 & 2.22 & Defense mechanisms \\
\hline $\mathrm{T}$ & 63 & 2.37 & Signal transduction mechanisms \\
\hline M & 116 & 4.36 & Cell wall/membrane biogenesis \\
\hline $\mathrm{N}$ & 8 & 0.30 & Cell motility \\
\hline Z & 0 & 0 & Cytoskeleton \\
\hline W & 0 & 0 & Extracellular structures \\
\hline$U$ & 29 & 1.09 & Intracellular trafficking secretion \\
\hline $\mathrm{O}$ & 78 & 2.93 & Posttranslational modification, protein turnover, chaperones \\
\hline $\mathrm{C}$ & 120 & 4.51 & Energy production conversion \\
\hline G & 172 & 6.47 & Carbohydrate transport metabolism \\
\hline $\mathrm{E}$ & 227 & 8.53 & Amino acid transport metabolism \\
\hline $\mathrm{F}$ & 74 & 2.78 & Nucleotide transport metabolism \\
\hline $\mathrm{H}$ & 108 & 4.06 & Coenzyme transport metabolism \\
\hline I & 67 & 2.52 & Lipid transport metabolism \\
\hline $\mathrm{P}$ & 192 & 7.22 & Inorganic ion transport metabolism \\
\hline Q & 43 & 1.62 & Secondary metabolites biosynthesis, transport catabolism \\
\hline $\mathrm{R}$ & 337 & 12.67 & General function prediction only \\
\hline S & 229 & 8.61 & Function unknown \\
\hline- & 266 & 10 & Not in COGs \\
\hline
\end{tabular}

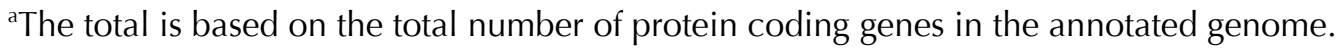




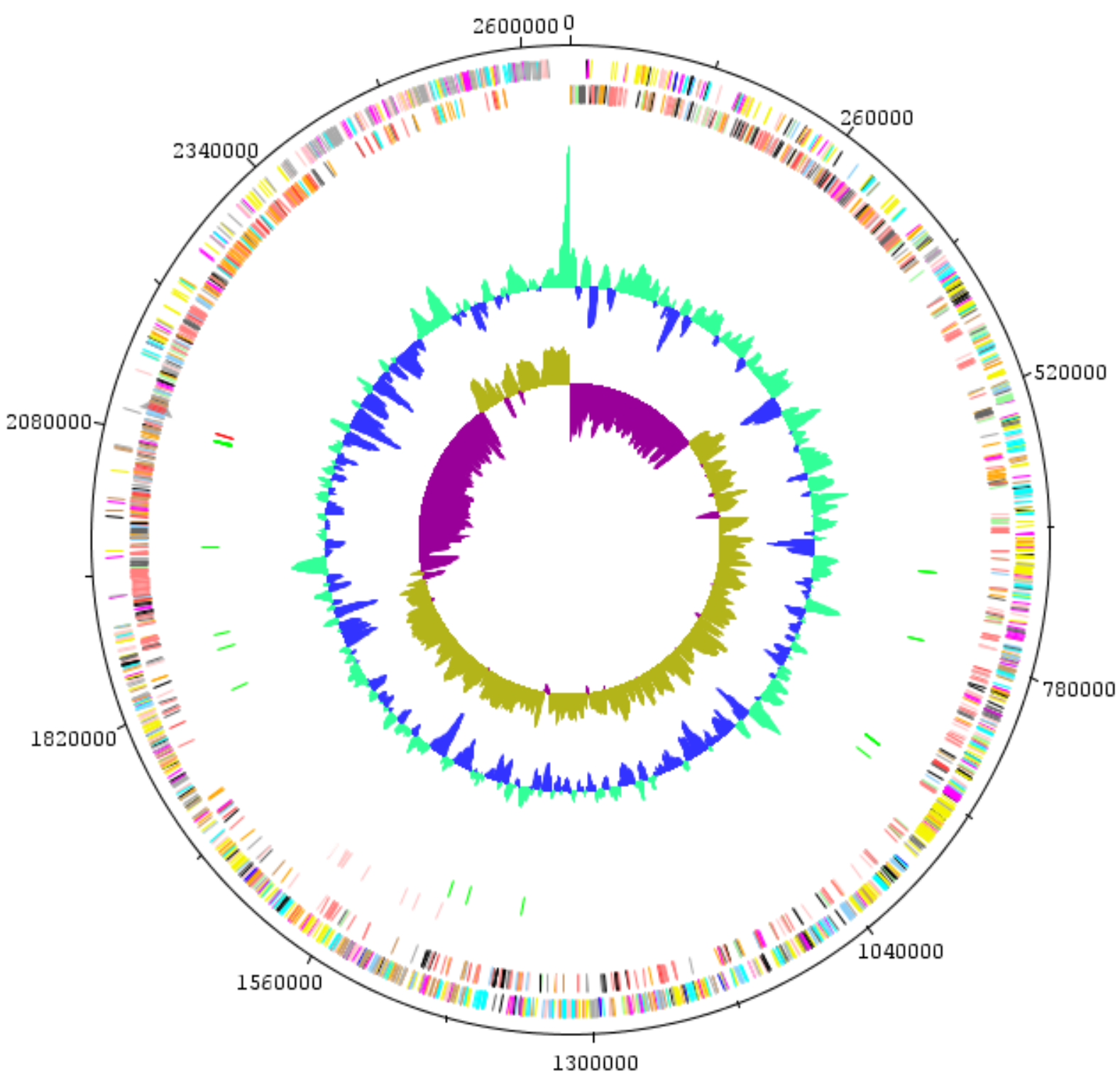

Figure 4. Graphical circular map of the chromosome. From outside to the center: Genes on the forward strand (colored by COG categories), genes on the reverse strand colored by COG categories), RNA genes (tRNAs green, rRNAs red), GC content, and GC skew.

S. aureus subsp. anaerobius encodes genes related to oxidative stress protection, including two intact superoxide dismutase genes and intact cytochrome quinol oxidase genes, which mediate oxidative metabolism [36]. Contrary to $S$. aureus, $S$. aureus subsp. anaerobius encodes an impaired catalase gene [37]. S. aureus subsp. anaerobius genome contains one intact Staphylococcus phage 2638A [38] and one incomplete Staphylococcus phage PT1028 [38] but no detectable CRISPERs. No bacteriophage was detected by electron microscopic visualization of 100 fields. A tetracycline resistance gene was found, although the strain is susceptible to tetracycline in-vitro.

\section{Comparative genomics}

The genome of $S$. aureus strains ranged between 2.67 to $3 \mathrm{Mb}$ and contains between zero and three plasmids. Average pairwise amino acid sequence identity of $98 \%$ and partial colinearity were observed between $S$. aureus and $S$. aureus subsp. anaerobius chromosomes. Reads of $S$. aureus subsp. anaerobius were not mapped against all $S$. aureus plasmids. S. aureus subsp. anaerobius strain ST1464 contains S. aureus virulence genes 
including cha collagen binding protein, ica $\mathrm{R}$ ica operon transcriptional regulator, icaA intercellular adhesion protein $\mathrm{A}$, icaD intercellular adhesion protein $\mathrm{D}$, ica $\mathrm{B}$ intercellular adhesion protein $\mathrm{B}$, icaC intercellular adhesion protein $\mathrm{C}$, aur zinc metalloproteinase aureolysin gene, geh glycerol ester hydrolase gene, isdB conserved hypothetical protein, hysA hyaluronate lyase precursor, $s d r C$ beta-neurexin binding protein gene, eta exfoliative toxin A and sea staphylococcal enterotoxin A precursor gene. However, it lacks genes encoding the serine protease, the clumping factor CIFA, enterotoxin B, adenosine synthase $A$ and toxic shock syndrome toxin, panton-valentine toxin and staphylokinase SAK. The extracellular adherence protein Eap gene is interrupted by a stop codon. Based on its genome, an in-silico multilocus sequence typing (Figure 6) indicates that $S$. aureus subsp. anaerobius emerged from $S$. aureus as a clone with impaired catalase and host adaptation. This species illustrates that specialization of pathogens is associated with gene loss, not with gene gain.

Table 4. Genome statistics

\begin{tabular}{lrr}
\hline Attribute & Value & \% of total \\
\hline Genome size (bp) & $2,604,446$ & 100 \\
DNA coding region (bp) & $2,154,549$ & 82.72 \\
DNA G+C content (bp) & $8,510,011$ & 32.7 \\
Total genes & 2,712 & 100 \\
RNA genes & 52 & 1.9 \\
Protein-coding genes & 2,660 & 98.08 \\
Genes assigned to COGs & 2,120 & 78.17 \\
Genes assigned to pfam & 2,148 & 79.2 \\
Genes with peptide signals & 146 & 5.38 \\
Genes with transmembrane helices & 680 & 25.07 \\
\hline
\end{tabular}

${ }^{a}$ The total is based on either the size of the genome in base pairs or the total number of protein coding genes in the annotated genome.

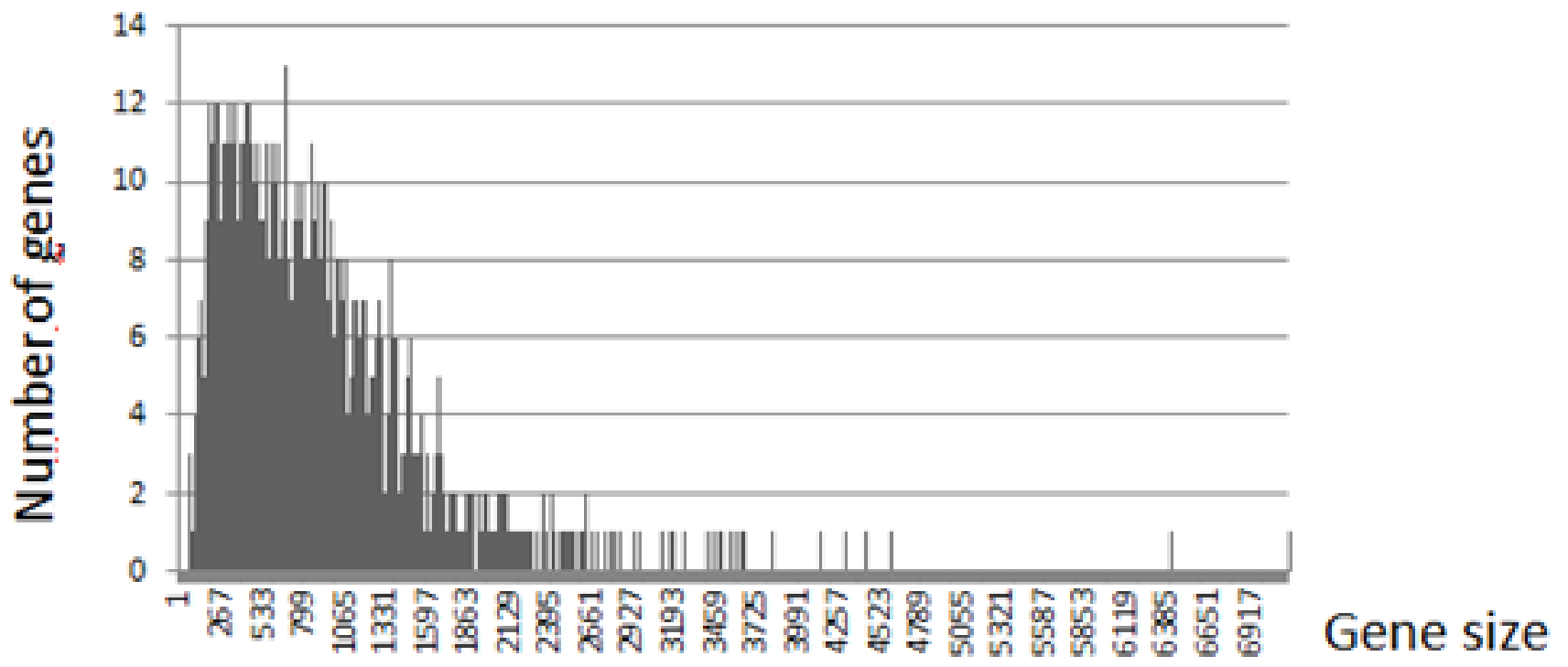

Figure 5. Graphical distribution of ORF size in the chromosome. 


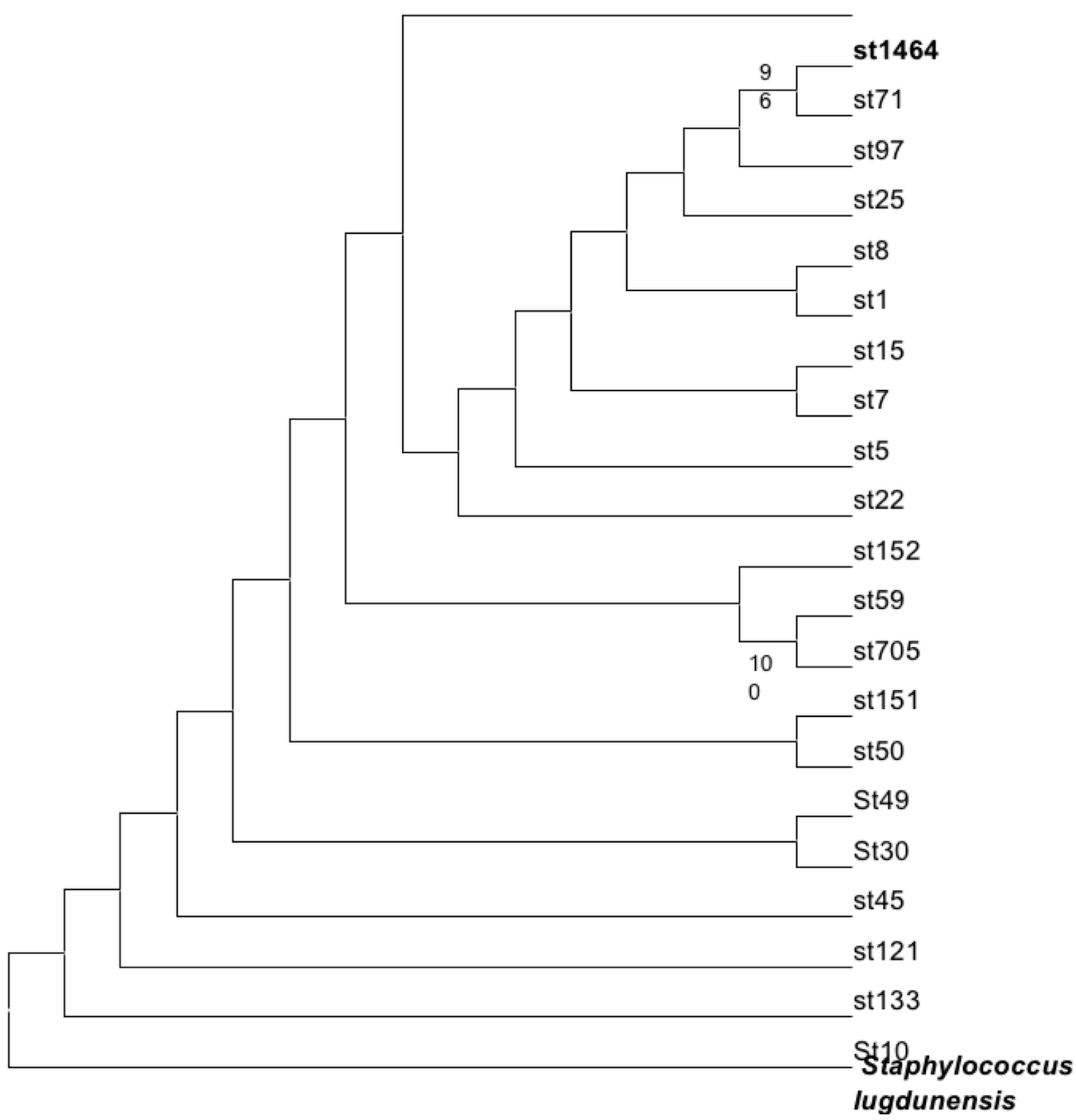

Figure 6. Maximum likelihood tree based on in-silico multilocus sequence typing of six genes (Acetyl-CoA acetyltransferase, putative glycerol uptake facilitator protein, shikimate 5-dehydrogenase, guanylate kinase, triosephosphate isomerase and putative phosphate acetyltransferase). Derived sequence types (St) are indicated at the end of each branch. It shows the relationship of S. aureus subsp. anaerobius with other S. aureus (ST 1464) and Staphylococcus lugdunensis as an external root. Only bootstrap values 90\% were indicated at nodes. 


\section{Acknowledgement}

This study was supported by Unité de Recherche sur les Maladies Infectieuses et Tropicales Emergentes.

\section{References}

1. De la Fuente R, Suarez G, Schleifer KH. Staphylococcus aureus subsp. anaerobius subsp. nov., the causal agent of abscess disease of sheep. Int J Syst Bacteriol 1985; 35:99-102. http://dx.doi.org/10.1099/00207713-35-1-99

2. Alhendi AB, al-Sanhousi SM, al-Ghasnawi YA, Madawi M. An outbreak of abscess disease in goats in Saudi Arabia. Zentralb/ Veterinarmed [C] 1993; 40:646-651. PubMed

3. Bajmócy E, Fazekas B, Tanyi J. An outbreak of Morel's disease (a contagious sheep disease accompanied by abscess formation) in Hungary. Acta Vet Hung 1984; 32:9-13. PubMed

4. Møller K, Agerholm JS, Ahrens P, Jensen NE, Nielsen TK. Abscess disease, caseous lymphadenitis, and pulmonary adenomatosis in imported sheep. I Vet Med B Infect Dis Vet Public Health 2000; 47:55-62. PubMed

http://dx.doi.org/10.1046/j.1439$\underline{0450.2000 .00310 . x}$

5. Szaluś-Jordanow O, Chrobak D, Pyrgiel M, Lutyńska A, Kaba J, Czopowicz M, Witkowski L, Kizerwetter-Świda M, Binek M, Frymus T. PFGE and AFLP genotyping of Staphylococcus aureus subsp. anaerobius isolated from goats with Morel's disease. Arch Microbiol 2012; Epub ahead of print. PubMed

6. Elbir H, Feil EJ, Drancourt M, Roux V, El Sanousi SM, Eshag M, Colque-Navarro P, Kühn I, Flock JI. Ovine clone ST1464: a predominant genotype of Staphylococcus aureus subsp. anaerobius isolated from sheep in Sudan. J Infect Dev Ctries 2010; 4:235-238. PubMed http://dx.doi.org/10.3855/jidc.632

7. de la Fuente $R$, Ballesteros $C$, Bautista $V$, Medina A, Orden JA, Domínguez-Bernal G, Vindel A. Staphylococcus aureus subsp. anaerobius isolates from different countries are clonal in nature. Vet Microbiol 2011; 150:198-202. PubMed http://dx.doi.org/10.1016/j.vetmic.2010.12.022

8. Peake SL, Peter JV, Chan L, Wise RP, Butcher AR, Grove DI. First report of septicemia caused by an obligately anaerobic Staphylococcus aureus infection in a human. J Clin Microbiol 2006;

44:2311-2313. PubMed http://dx.doi.org/10.1128/JCM.02125-05

9. Field D, Garrity G, Gray T, Morrison N, Selengut J, Sterk P, Tatusova T, Thomson N, Allen MJ, Angiuoli SV, et al. The minimum information about a genome sequence (MIGS) specification. Nat Biotechnol 2008; 26:541-547. PubMed http://dx.doi.org/10.1038/nbt1360

10. Woese CR, Kandler O, Wheelis ML. Towards a natural system of organisms: proposal for the domains Archae, Bacteria, and Eukarya. Proc Natl Acad Sci USA 1990; 87:4576-4579. PubMed http://dx.doi.org/10.1073/pnas.87.12.4576

11. Gibbons NE, Murray RGE. Proposals Concerning the Higher Taxa of Bacteria. Int J Syst Bacteriol 1978; 28:1-6. http://dx.doi.org/10.1099/00207713-28-1-1

12. Garrity GM, Holt JG. The Road Map to the Manual. In: Garrity GM, Boone DR, Castenholz RW (eds), Bergey's Manual of Systematic Bacteriology, Second Edition, Volume 1, Springer, New York, 2001, p. 119-169.

13. Murray RGE. The Higher Taxa, or, a Place for Everything...? In: Holt JG (ed), Bergey's Manual of Systematic Bacteriology, First Edition, Volume 1, The Williams and Wilkins Co., Baltimore, 1984, p. 31-34.

14. List of new names and new combinations previously effectively, but not validly, published. List no. 132. Int / Syst Evol Microbiol 2010; 60:469472. http://dx.doi.org/10.1099/ijs.0.022855-0

15. Ludwig W, Schleifer KH, Whitman WB. Class I. Bacilli class nov. In: De Vos P, Garrity G, Jones D, Krieg NR, Ludwig W, Rainey FA, Schleifer KH, Whitman WB (eds), Bergey's Manual of Systematic Bacteriology, Second Edition, Volume 3, Springer-Verlag, New York, 2009, p. 19-20.

16. Skerman VBD, McGowan V, Sneath PHA. Approved Lists of Bacterial Names. Int J Syst Bacteriol 1980; 30:225-420. http://dx.doi.org/10.1099/00207713-30-1-225

17. Prévot AR. In: Hauderoy P, Ehringer G, Guillot G, Magrou. J., Prévot AR, Rosset D, Urbain A (eds), Dictionnaire des Bactéries Pathogènes, Second Edition, Masson et Cie, Paris, 1953, p. 1-692.

18. List Editor. List of new names and new combinations previously effectively, but not validly, published. List no. 132. Int J Syst Evol Microbiol 
2010; 60:469-472.

http://dx.doi.org/10.1099/ijs.0.022855-0

19. Schleifer KH, Bell JA. Family VIII. Staphylococcaceae fam. nov. In: De Vos P, Garrity G, Jones D, Krieg NR, Ludwig W, Rainey FA, Schleifer KH, Whitman WB (eds), Bergey's Manual of Systematic Bacteriology, Second Edition, Volume 3, Springer-Verlag, New York, 2009, p. 392.

20. Rosenbach FJ. In: Bergmann JF (ed), Microorganismen bei den Wund-InfectionsKrankheiten des Menschen., Wiesbaden, 1884, p. 1-122.

21. Baird-Parker AC. Genus II. Staphylococcus Rosenbach 1884, 18. In: Buchanan RE, Gibbons NE (eds), Bergey's Manual of Determinative Bacteriology, Eighth Edition, The Williams and Wilkins Co., Baltimore, 1974, p. 483-489.

22. Judicial Commission. Opinion 17. Conservation of the Generic name Staphylococcus Rosenbach, Designation of Staphylococcus aureus Rosenbach as the Nomenclatural Type of the Genus Staphylococcus Rosenbach, and Designation of the Neotype culture of Staphylococcus aureus Rosenbach. Int Bull Bacteriol Nomencl Taxon 1958; 8:153-154.

23. Schleifer KH, Bell JA. Family VIII. Staphylococcaceae fam. nov. In: De Vos P, Garrity G, Jones D, Krieg NR, Ludwig W, Rainey FA, Schleifer KH, Whitman WB (eds), Bergey's Manual of Systematic Bacteriology, Second Edition, Volume 3, Springer-Verlag, New York, 2009, p. 392.

24. Ashburner M, Ball CA, Blake JA, Botstein D, Butler $\mathrm{H}$, Cherry JM, Davis AP, Dolinski K, Dwight SS, Eppig JT, et al. Gene Ontology: tool for the unification of biology. Nat Genet 2000; 25:25-29. PubMed http://dx.doi.org/10.1038/75556

25. Björkqvist $M$, Söderquist B, Törnqvist $E$, Sjöberg $L$, Fredlund H, Kühn I, Colque-Navarro P, Schollin J. Phenotypic and genotypic characterisation of blood isolates of coagulase-negative staphylococci in the newborn. APMIS 2002; 110:332-339. PubMed http://dx.doi.org/10.1034/j.1600$\underline{0463.2002 .100408 . x}$

26. Tamura K, Peterson D, Peterson N, Stecher G, Nei M, Kumar S. MEGA5: molecular evolutionary genetics analysis using maximum likelihood, evolutionary distance, and maximum parsimony methods. Mol Biol Evol 2011; 28:2731-2739. PubMed http://dx.doi.org/10.1093/molbev/msr121
27. Seng $P$, Drancourt M, Gouriet F, La SB, Fournier $\mathrm{PE}$, Rolain JM, Raoult D. Ongoing revolution in bacteriology: routine identification of bacteria by matrix-assisted laser desorption ionization timeof-flight mass spectrometry. Clin Infect Dis 2009; 49:543-551. PubMed http://dx.doi.org/10.1086/600885

28. Hyatt D, Chen GL, Locascio PF, Land ML, Larimer FW, Hauser LJ. Prodigal: prokaryotic gene recognition and translation initiation site identification. BMC Bioinformatics 2010; 11:119. PubMed http://dx.doi.org/10.1186/1471-2105-11-119

29. Laslett D, Canback B. ARAGORN, a program to detect tRNA genes and tmRNA genes in nucleotide sequences. Nucleic Acids Res 2004; 32:1116. PubMed http://dx.doi.org/10.1093/nar/gkh152

30. Marchler-Bauer A, Panchenko AR, Shoemaker BA, Thiessen PA, Geer LY, Bryant SH. CDD: a database of conserved domain alignments with links to domain three-dimensional structure. Nucleic Acids Res 2002; 30:281-283. PubMed http://dx.doi.org/10.1093/nar/30.1.281

31. Tatusov RL, Galperin MY, Natale DA, Koonin EV. The COG database: a tool for genome-scale analysis of protein functions and evolution. Nucleic Acids Res 2000; 28:33-36. PubMed http://dx.doi.org/10.1093/nar/28.1.33

32. Sonnhammer EL, Eddy SR, Durbin R. 1997. Pfam: a comprehensive database of protein domain families based on seed alignments. Proteins 2000; 28:405-420. http://dx.doi.org/10.1002/(SICI)10970134(199707)28:3<405::AID-PROT10>3.0.CO;2$\underline{\mathrm{L}}$

33. Krogh A, Larsson B, von Heijne G, Sonnhammer ELL. Predicting transmembrane protein topology with a hidden Markov model: Application to complete genomes. J Mol Biol 2001; 305:567580. PubMed http://dx.doi.org/10.1006/jmbi.2000.4315

34. Bendtsen JD, Nielsen H, von Heijne G, Brunak S. Improved prediction of signal peptides: SignalP 3.0. J Mol Biol 2004; 340:783-795. PubMed http://dx.doi.org/10.1016/j.jmb.2004.05.028

35. Zhou Y, Liang Y, Lynch KH, Dennis JJ, Wishart DS. PHAST: a fast phage search tool. Nucleic Acids Res 2011;39(Web Server issue):W347-52.

36. Lewis JP, Iyer D, Anaya-Bergman C. Adaptation of Porphyromonas gingivalis to microaerophilic conditions involves increased consumption of formate and reduced utilization of lactate. Microbiology 2009; 155:3758-3774. PubMed http://dx.doi.org/10.1099/mic.0.027953-0 
37. Sanz R, Marín I, Ruiz-Santa-Quiteria JA, Orden JA, Cid D, Diez RM, Silhadi KS, Amils R, de la Fuente R. Catalase deficiency in Staphylococcus aureus subsp. anaerobius is associated with natural loss-of-function mutations within the structural gene. Microbiology 2000; 146:465-475. PubMed
38. Kwan T, Liu J, DuBow M, Gros P, Pelletier J. The complete genomes and proteomes of 27 Staphylococcus aureus bacteriophages. Proc Natl Acad Sci USA 2005; 102:5174-5179. PubMed http://dx.doi.org/10.1073/pnas.0501140102 